\title{
High velocity impact test on glass fibre reinforced polymer (GFRP) using a single stage gas gun (SSGG) - an experimental based approach
}

\begin{abstract}
The aim of this work is to study the effect of thickness and type of bullet in impact test on structures made from a composite material. The composite material used in this study was Glass Fibre Reinforced Polymer (GFRP). This material was fabricated to produce laminated plate specimens with dimension of $100 \mathrm{~mm} \times 100 \mathrm{~mm}$ and $6,8,10$, and $12 \mathrm{~mm}$ thickness. The impact test was performed using a Single Stage Gas Gun (SSGG) with blunt, hemispherical, and conical types of bullets. The gas gun pressure was set to 5, 10, 15 and 20 bar. In the tests, gas gun pressure, bullet type and specimen thickness were varied to ascertain the influence of these parameters on the materials response. The relation between impact force with gas pressure, type of bullets and specimens thickness are presented and discussed. The best thickness for GFRP was identified according to the impact results. From the impact tests conducted, it was found that at the same amount of pressure, the higher the thickness, the bigger the impact force because as the specimen thickness increases, the amount of impact force absorbed by the specimen is higher.
\end{abstract}

Keyword: Glass fibre reinforced polymer (GFRP); High velocity impact (HVI); Impact force (F); Single stage gas gun (SSGG) 